
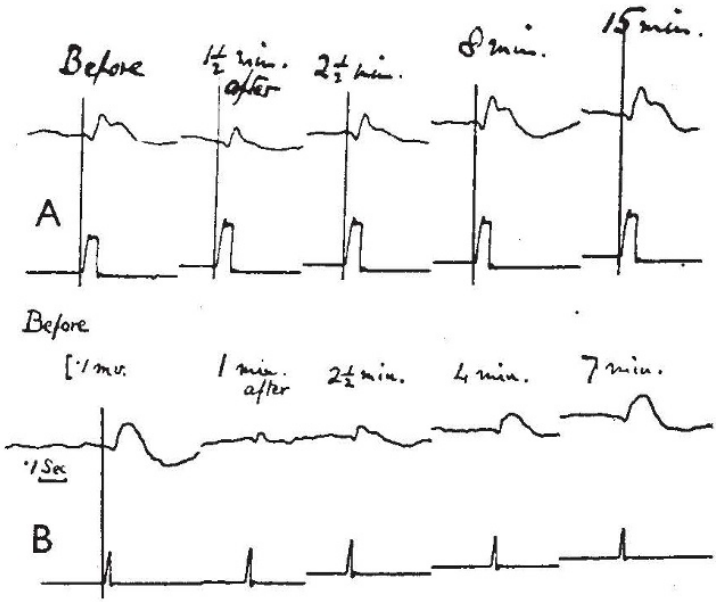

Fig. 2. EFHECT OF LIGHT ADAPTATION ON THE RESPONSE TO ORANGE-RED AND GREEX LIGHT.

4: Wratten fHTter No. 71. Central Wave-Length $640 \mathrm{~m} \mu$. $B$ : Wratten filter No. 73. Centrat Wave-Length $575 \mathrm{~m} \mu$.

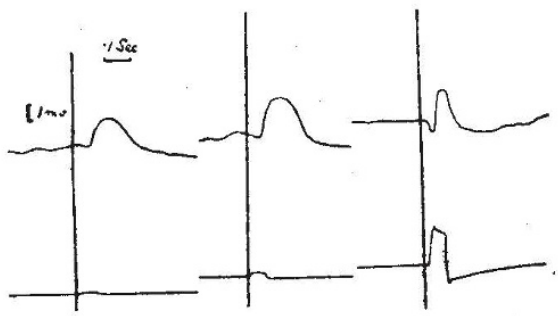

Fig. 3. RESPONSE TO FLASHES OF WHITE IIGHT OF INCREASING INTENSITY.

greatly affected by dark adaptation : it may be too small to detect (that is, less than about 20 microvolts) in the first few minutes after the eye has been exposed to a bright sky, but it will then increase steadily as dark adaptation proceeds, reaching 300 microvolts or more after 20 minutes.

With light of intermediate wave-length, the response seems to be compounded of both the rapid and the slow effects. The relative size of the two components depends on the degree of dark adaptation and can be varied by restricting the field to the central or peripheral parts of the retina, by altering the duration of the flash, or, with repetitive stimuli, by altering the frequency. Under standard conditions, the slower component is greatest with green-blue light and the rapid diphasic component with orange. The dual character of the response can be seen from Fig. 2, which gives a series of records made with orange-red light (Wratten filter No. 71) and another with green (filter No. 73). Initially the eye is moderately dark adapted, and the slow part of the response is prominent, more so in the records with green light since the slow component is relatively larger with green. Exposing the eye for a few minutes to a bright sky abolishes the slow effect, leaving only the initial diphasic response, but the slow component reappears after a few minutes and becomes larger and larger as dark adaptation proceeds.

With white light of moderate intensity the response has both components, since there is the initial negativity as well as the slower positive wave which can be increased by dark adaptation. With a bright flash, however, the slower component can no longer be seen (Fig. 3). The change in form suggests that at high intensities the photopic mechanism inhibits the scotopic, though other explanations are possible. When red or blue light is used, the form of the response, rapid or slow, is unaffected by a change in intensity within the limits of the apparatus in use.

The idea that the electric response of the retina has both a rod and a cone component is not new: it has been advocated particularly by Chaffee, Bovie and Hampson ${ }^{1}$, but in animals other than man it has been difficult to establish a clear separation. It is easier to do this in man because the sensory perform. ance of the human eye is so much better known.

Physiological Laboratory,

E. D. ADrian. Cambridge.

Aug. 26. ${ }^{1}$ Chaffee, E. L., Bovie, W. T., and Hampson, A., J. Opt. Soc. Amer.,

\section{Proteases of Takadiastase}

Solutions of takadiastase (Parke, Davis and Co., Ltd.) split casein, gelatin, leucylglycylglycine, leucylglycine and chloroacetyltyrosine. The same substrates undergo hydrolysis when the enzyme solutions are subjected to prolonged dialysis in 'Cellophane' bags against running tap water. If, however, the dialysed solutions are filtered by suction through kieselguhr layers, only leucylglycylglycine of all the above substrates is split. The addition of dialysate, inactivated by heating, does not restore the activity of the filtrates towards the other four substrates.

The carboxypolypeptidase component appears to be relatively stable, for the dialysed solutions retain about 50 per cent of their activity towards chloroacetyltyrosine after being kept at $37^{\circ}$ for ten days. Under the same conditions, the dialysates lose 70-80 per cent of their activity towards casein and gelatin, whereas the activity towards leucylglycylglycine remains almost unchanged.

Leucylglutamic acid anhydride is not hydrolysed by the dialysates or by the undialysed solutions.

A detailed report on the foregoing and further experiments with the proteolytic enzymes of commercial takadiastase will be published elsewhere.

Department of Biological and

N. LiCHTENSTEIN.

Colloidal Chemistry,

Hebrew University,

Jerusalem.

July 7.

\section{Terminology of Lipoid-Protein Complexes}

IN an otherwise excellent review by Lovern ${ }^{1}$ a statement occurs on p. 32 that demands correction. In discussing the terminology of lipoid-protein complexes, Lovern rejects Macheboeuf's term 'cénapse', in favour of 'complex', claiming that the English spelling of 'cénapse' is 'synapse', to which anatomy has a prior claim.

'Cénapse' was compounded by Macheboeuf ${ }^{2}$ from

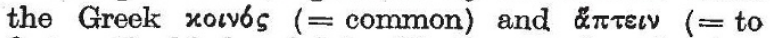
fasten, tie, bind or join), with the meaning of union, bonding, binding, joining, etc. ("liaison, jonction"). 